(2) Open Access Full Text Article

\title{
Lymphocyte To High-Density Lipoprotein Ratio As A New Indicator Of Inflammation And Metabolic Syndrome
}

This article was published in the following Dove Press journal: Diabetes, Metabolic Syndrome and Obesity: Targets and Therapy

\author{
Haishan Chen* \\ Chongxiang Xiong \\ Xiaofei Shao* \\ Jing Ning \\ Peichun Gao \\ Hua Xiao \\ Yunying Chen \\ Ziliang Zou \\ Guobao Hong \\ Xiaolin Li \\ Mengjiao Shao \\ Jieli Sheng \\ Xingyan Yang \\ $\mathrm{Xu}$ You \\ Hequn Zou
}

Department of Nephrology, The Third Affiliated Hospital, Southern Medical University, Guangzhou 510630, People's Republic of China

*These authors contributed equally to this work
Correspondence: Hequn Zou Department of Nephrology, The Third Affiliated Hospital, Southern Medical University, 183 Zhongshan West Avenue, Tianhe District, Guangzhou 5I0630, People's Republic of China

Email Hequnzou@hotmail.com
Purpose: Metabolic syndrome (MetS), which is a global public health problem, is a state of chronic low-grade inflammation. This study looked at the changes in hematological parameters and the predictive value of the lymphocyte to high-density lipoprotein cholesterol (HDL-C) ratio (LHR) as a new index in subjects with and without MetS in coastal cities in southern China.

Patients and methods: In this cross-sectional study, there were 852 participants $(n=598$ with MetS and $n=254$ without MetS). MetS was defined in accordance with the National Cholesterol Education Program, Adult Treatment Panel III (NCEP-ATP III) criteria.

Results: MetS was positively correlated with white blood cell count, total lymphocyte count, neutrophil count, red blood cell count, hematocrit, hemoglobin, and high-sensitivity Creactive protein levels $(p<0.05)$. In addition, there was a positive correlation between LHR and the number of metabolic risk factors for MetS. In a logistic regression analysis, LHR (odds ratio: 4.117; 95\% CI: 2.766-6.309; $p<0.001$ ) was an independent predictor of MetS. When a receiver operating characteristic (ROC) curve analysis was used to assess the value of LHR for predicting MetS, the area under the curve yielded a cut-off value of 1.657, with a sensitivity of $65 \%$ and a specificity of $64 \%(p<0.0001)$.

Conclusion: In summary, MetS can involve changes in blood parameters, and LHR may be a useful marker of inflammation to assess the presence and severity of MetS.

Keywords: inflammation, marker, metabolic syndrome, lymphocyte to high-density lipoprotein cholesterol ratio

\section{Introduction}

MetS involves a complex group of metabolic disorders, including central obesity, systemic hypertension, insulin resistance, and atherogenic dyslipidemia (especially hypertriglyceridemia and decreased high-density lipoprotein cholesterol [HDL-C] levels), which increases the risk of cardiovascular and cerebrovascular diseases and diabetes. $^{1,2}$

As the incidence and prevalence of MetS increase globally, this non-communicable disease has become a major health hazard worldwide. ${ }^{3}$ The underlying pathophysiology of MetS has several hypothetical mechanisms, the most widely accepted of which involves insulin resistance. Other potential mechanisms include low-grade chronic inflammation and oxidative stress, as MetS is a prothrombotic and proinflammatory state. ${ }^{4}$ A growing body of evidence suggests that changes in hematological parameters, including white blood cell (WBC), red blood cell (RBC), 
and platelet counts, as markers of prothrombotic and proinflammatory states, may be associated with MetS. ${ }^{5-8}$

Reports on the changes in the number of lymphocytes in MetS patients are inconsistent. There have been reports of a decrease in the number of lymphocytes in MetS patients. ${ }^{9,10}$ However, some studies have found that lymphocytes proliferate and participate in the pathogenesis of MetS. ${ }^{11,12}$ HDL-C has anti-inflammatory, antioxidant, and antithrombotic properties and is a protective factor in MetS. ${ }^{13,14}$ Therefore, we suspected that the lymphocyte to HDL-C ratio (LHR) is a potential new inflammatory marker. We aimed to assess the associations of hematological parameters (including the new marker LHR) with the presence and severity of MetS.

\section{Methods}

\section{Study Population}

This cross-sectional survey was conducted from January to April 2018 in six communities in Wanzhai Town, Zhuhai City, on the southern coast of China. The study was conducted in accordance with the Declaration of Helsinki and was approved by the Ethics Committee of the Third Affiliated Hospital of Southern Medical University. All subjects signed a written informed consent form. A total of 852 ( $n=254$ with MetS and $n=598$ without MetS) residents were enrolled in the survey.

MetS was diagnosed if at least three of the following five items of the National Cholesterol Education Program, Adult Treatment Panel III (NCEP ATP III) criteria were met:

1. Fasting triglyceride level $\geq 1.7 \mathrm{mmol} / \mathrm{L}$ or treated with drugs.

2. HDL-C levels $<1.1 \mathrm{mmol} / \mathrm{L}$ for women and $<0.9$ $\mathrm{mmol} / \mathrm{L}$ for men or treated with drugs.

3. Fasting blood glucose $\geq 5.6 \mathrm{mmol} / \mathrm{L}$, treated with drugs, or previously diagnosed with type 2 diabetes mellitus.

4. Increased blood pressure: systolic blood pressure (SBP) $\geq 130 \mathrm{mmHg}$, diastolic blood pressure (DBP) $\geq 85 \mathrm{mmHg}$, treated with antihypertensive drugs, or previously diagnosed with hypertension.

5. Central obesity: waist circumference $\geq 90 \mathrm{~cm}$ for men and $\geq 80 \mathrm{~cm}$ for women.

Because the blood system is affected by many diseases, the following exclusion criteria were applied: use of antiplatelet drugs; abnormal liver function; abnormal renal function; heart disease; lung disease; gastrointestinal disease; autoimmune disease; malignant tumor; and acute or chronic infectious disease.

\section{Data Collection}

Questionnaires were used to collect data on age, gender, education, current smoking, current alcohol use, physical activity, and so on.

After resting for at least 5 mins, the blood pressure of each participant's left arm was measured with a mercury sphygmomanometer three times, and the mean of the three readings was calculated. Waist circumference was measured at the midpoint between the lower rib edge at the midline and the top of the hip bone.

All blood samples were collected after at least $10 \mathrm{~h}$ of fasting overnight. Blood samples collected in ethylenediaminetetraacetic acid (EDTA) anticoagulation tubes were used to analyze blood routine parameters, and blood samples collected in tubes containing inert separation gels were used to analyze the blood biochemistry. All blood samples were transported to the central laboratory of the Third Affiliated Hospital of Southern Medical University within $3 \mathrm{~h}$ for analysis. Serum creatinine, fasting blood glucose, high-sensitivity C-reactive protein (hsCRP), serum total cholesterol, serum triglycerides, and serum HDL-C were measured by colorimetry. Whole blood cell counts were assessed using a Sysmex XN-1000 analyzer (Sysmex Corporation, Kobe, Japan). The lymphocyte to HDL-C ratio (LHR) was calculated manually.

\section{Statistical Analysis}

All data were analyzed using SPSS (version 20). Continuous variables are presented as mean \pm standard deviation if they have a normal distribution, or as median and interquartile range if they do not. The categorical variables are expressed as frequencies and percentages.

The $t$-test was used to compare the differences in the means between the groups, while the Mann-Whitney $U$-test was used to compare the differences in the medians (These variables included Fasting plasma glucose, Serum triglycerides, Eosinophilic count, Basophilic count and hsCRP). The chi-square $\left(\chi^{2}\right)$ test was used for comparison of categorical variables. Correlation analysis was used to determine the association between MetS and variables (especially the hematological indicators). Binomial logistic regression analysis was used to identify the independent predictors of MetS, controlling for confounders. A receiver operating characteristic (ROC) curve analysis was 
used to assess the value of the novel indicator LHR for predicting MetS and to obtain the best cutoff value. Twotailed $p$ values $<0.05$ were considered significant.

\section{Results}

As can be seen from Table 1, compared with the MetS(-) group, the $\mathrm{MetS}(+)$ group was significantly older, had significantly higher proportions of men and smokers, and had significantly higher waist circumference, blood pressure, fasting plasma glucose, and triglyceride levels, while the proportion of individuals with an educational level of high school or above and HDL-C levels were significantly reduced $(p<0.01)$. In addition, in the $\operatorname{MetS}(+)$ group, the WBC count (and the counts of the WBC subcomponents), RBC count, hemoglobin, hematocrit, and hsCRP were also significantly increased. However, there were no significant differences in platelet count, platelet distribution width, or mean platelet volume $(p>0.05)$.

As shown in Table 2, in the correlation analysis, the severity of MetS was significantly positively correlated with WBC count, neutrophil count, total lymphocyte count, RBC count, hemoglobin, hematocrit, hsCRP, age, and education. Additionally, the correlation coefficient for LHR and MetS was $0.251(p<0.001)$.

To determine the independent predictors of the presence of MetS, the abovementioned continuous variables were subjected to binomial logistic regression analysis. The results showed that LHR, hemoglobin, and hsCRP were independent predictors of MetS (Table 3). As the outcome variable may be affected by many confounding factors, age, male gender, current smoking, current alcohol use, physical activity, and education level were adjusted for in Model 2, and Model 3 also adjusted for fasting blood glucose and waist circumference.

Figure 1 shows that the severity of MetS was proportional to lymphocyte to high-density lipoprotein ratio (LHR).

As shown in Figure 2, a ROC curve analysis was used to assess the value of three inflammatory markers (LHR, total lymphocyte count, and hsCRP) for predicting MetS in the study population.

The analysis showed that the cutoff value of LHR was 1.657 , the sensitivity was $65 \%$, the specificity was $64 \%$,

Table I Sociodemographic And Clinical Characteristics Of The Study Population (Frequency And Percentage/Mean \pm Standard Deviation)

\begin{tabular}{|c|c|c|c|}
\hline Variable & $\operatorname{MetS}(-)(n=598)$ & MetS(+) $(n=254)$ & $p$ \\
\hline Age (years) & $47.67 \pm 0.45$ & $56.48 \pm 0.53$ & $<0.001$ \\
\hline Male, n (\%) & $205(34.28)$ & $108(42.52)$ & 0.022 \\
\hline Current smoking, n (\%) & $61(10.20)$ & $38(14.96)$ & 0.047 \\
\hline Current alcohol use, n (\%) & $22(3.68)$ & $10(3.94)$ & 0.856 \\
\hline Educational attainment - high school or above, $\mathrm{n}$ (\%) & 293(49.00) & $88(34.64)$ & $<0.001$ \\
\hline Physical activity, n (\%) & $338(56.52)$ & $158(62.20)$ & 0.124 \\
\hline Waist circumference, $\mathrm{cm}$ & $83.44 \pm 0.38$ & $93.72 \pm 0.52$ & $<0.001$ \\
\hline Systolic blood pressure (SBP), $\mathrm{mmHg}$ & $126.15 \pm 0.72$ & $144.15 \pm 1.03$ & $<0.001$ \\
\hline Diastolic blood pressure (DBP), $\mathrm{mmHg}$ & $80.46 \pm 0.43$ & $89.69 \pm 0.56$ & $<0.001$ \\
\hline Fasting plasma glucose, $\mathrm{mmol} / \mathrm{L}$ & $4.85(4.56-5.14)$ & $5.70(4.99-6.59)$ & $<0.001$ \\
\hline Serum triglycerides, $\mathrm{mmol} / \mathrm{L}$ & $1.185(0.89-1.53)$ & $2.09(1.62-2.27)$ & $<0.001$ \\
\hline High-density lipoprotein cholesterol (HDL-C), mmol/L & $1.53 \pm 0.01$ & $1.32 \pm 0.02$ & $<0.001$ \\
\hline White blood cell count, $10^{9} / \mathrm{L}$ & $6.4 I \pm 0.06$ & $7.03 \pm 0.11$ & $<0.001$ \\
\hline Neutrophil count, $10^{9} / \mathrm{L}$ & $3.44 \pm 0.05$ & $3.77 \pm 0.08$ & $<0.001$ \\
\hline Lymphocyte count, $10^{9} / \mathrm{L}$ & $2.28 \pm 0.03$ & $2.52 \pm 0.04$ & $<0.001$ \\
\hline Eosinophilic count, $10^{9} / \mathrm{L}$ & $0.13(0.08-0.20)$ & $0.15(0.09-0.24)$ & 0.003 \\
\hline Basophilic count, $10^{9} / \mathrm{L}$ & $0.02(0.02-0.03)$ & $0.03(0.02-0.04)$ & 0.003 \\
\hline Mononuclear count, $10^{9} / \mathrm{L}$ & $0.50 \pm 0.01$ & $0.52 \pm 0.01$ & 0.04 \\
\hline Red blood cell count, $10^{12} / \mathrm{L}$ & $4.85 \pm 0.02$ & $4.96 \pm 0.03$ & 0.006 \\
\hline Hemoglobin, $g / L$ & $139.85 \pm 0.55$ & $145.95 \pm 0.82$ & $<0.001$ \\
\hline Hematocrit & $0.43 \pm 0.001$ & $0.45 \pm 0.002$ & $<0.001$ \\
\hline Platelet count, $10^{9} / \mathrm{L}$ & $265.55 \pm 2.45$ & $267.1 \pm 3.63$ & 0.723 \\
\hline Mean platelet volume, $\mathrm{fL}$ & $10.34 \pm 0.04$ & $10.32 \pm 0.05$ & 0.820 \\
\hline Platelet distribution width, $\mathrm{fL}$ & $11.92 \pm 0.08$ & $12.07 \pm 0.13$ & 0.303 \\
\hline hypersensitive C-reactive protein (hsCRP), mg/L & $1.09(0.001-1.98)$ & $1.93(1.19-2.93)$ & $<0.001$ \\
\hline
\end{tabular}


Table 2 Correlation Analysis Between MetS Severity And Hematological Indicators

\begin{tabular}{|l|l|l|l|}
\hline Variable & $\mathbf{R}$ & $\mathbf{P}$ & $\begin{array}{l}\text { Grading Of } \\
\text { The } \\
\text { Correlation } \\
\text { Results }\end{array}$ \\
\hline White blood cell count & 0.143 & $<0.00$ I & Small \\
Neutrophil count & 0.10 I & $<0.00$ I & Small \\
Lymphocyte count & 0.142 & $<0.00$ I & Small \\
Eosinophilic count & 0.084 & $<0.00$ I & Small \\
Basophilic count & 0.093 & $<0.00$ I & Small \\
Mononuclear count & 0.057 & $<0.05$ & Small \\
Red blood cell count & 0.123 & $<0.00$ I & Small \\
Hemoglobin & 0.172 & $<0.00$ I & Small \\
Hematocrit & 0.171 & $<0.00$ I & Small \\
Lymphocyte to HDL-C ratio & 0.25 I & $<0.00$ I & Small \\
hsCRP & 0.279 & $<0.00$ I & Small \\
Smoking & 0.077 & $<0.05$ & Small \\
Education attainment - high & -0.132 & $<0.00$ I & Small \\
school or above & & & \\
Age & 0.314 & $<0.00$ I & Medium \\
Male & -0.078 & $<0.05$ & Small \\
\hline
\end{tabular}

Abbreviation: hsCRP, hypersensitive C-reactive protein.

and the area under the curve was $0.694(p<0.001 ; 95 \%$ confidence interval [CI]: 0.655-0.732). The area under the curve values for total lymphocyte count and hsCRP were $0.609(p<0.001 ; 95 \% \quad \mathrm{CI}: \quad 0.568-0.650)$ and 0.675 $(p<0.001,95 \%$ CI: $0.638-0.713)$, respectively.

\section{Discussion}

The main findings of this study were as follows: (i) The hematological parameters of patients with MetS were partially altered compared with those of patients without MetS. These changes mainly involved the parameters related to WBC and RBC counts and the counts of their subcomponent cells, while the platelet-related parameters were unchanged. (ii) LHR increased as the number of MetS risk factors increased, showing a positive correlation. (iii) ROC curve analysis showed that LHR had a higher predictive value for MetS than total lymphocyte count and hsCRP. To the best of our knowledge, this study is the first clinical study to focus on the relationship between LHR as a novel and indirect inflammatory marker and the presence and severity of MetS.

Our data were consistent with some of the previous reports of changes in blood parameters in patients with MetS. ${ }^{14-25}$ These associations between blood parameters and MetS can be explained by the contribution of insulin resistance to the development of MetS. Insulin influences metabolism and proliferation. Insulin and insulin growth factors, I and II can promote the proliferation of RBC and WBC. ${ }^{26-30}$ In addition, proinflammatory cytokines such as interleukin (IL)-8 and tumor necrosis factor (TNF)- $\alpha$, which are released by perivascular white adipose tissue, can cause leukocytosis. ${ }^{31,32}$

Elevated hematocrit increases blood viscosity and peripheral blood flow resistance, further limiting glucose, insulin, and oxygen transport to metabolically active tissues and increasing the risk of insulin resistance. ${ }^{21}$ Hemoglobin can induce vasoconstriction by limiting nitric oxide in vascular smooth muscle cells, which explains the positive correlation between hemoglobin levels and hypertension. ${ }^{33}$

Elevated WBC counts may result in low levels of chronic inflammation that impair endothelial function and thereby affect the production of nitric oxide and prostacyclin, ultimately leading to vasoconstriction and hypertension. Under stimulation by inflammatory factors, leukocyte properties are altered, with an increase in the tendency to adhere to the vascular endothelium, which may result in increased capillary leukocytosis and a subsequent increase in vascular resistance. ${ }^{34,35}$ Adiponectin inhibits the production of macrophage chemokine ligands and reduces the recruitment of T-lymphocytes in atherosclerosis. ${ }^{36}$ Low plasma adiponectin levels in obese individuals often lead to chronic inflammation, resulting in metabolic disorders. In addition, mature

Table 3 Binomial Logistic Regression Analysis Showing Independent Predictors Of MetS

\begin{tabular}{|c|c|c|c|c|c|c|}
\hline \multirow[t]{2}{*}{ Variable } & \multicolumn{2}{|l|}{ Model I } & \multicolumn{2}{|l|}{ Model 2} & \multicolumn{2}{|l|}{ Model 3} \\
\hline & OR $(95 \% \mathrm{CI})$ & $p$ & OR $(95 \% \mathrm{CI})$ & $p$ & OR $(95 \% \mathrm{CI})$ & $p$ \\
\hline Hemoglobin & $1.022(1.010-1.035)$ & $<0.001$ & $1.041(1.023-1.059)$ & $<0.001$ & $1.032(1.012-1.053)$ & $<0.05$ \\
\hline LHR & $2.46 \mid(1.914-3.164)$ & $<0.001$ & $3.140(2.360-4.177)$ & $<0.001$ & $2.917(2.110-4.033)$ & $<0.001$ \\
\hline hsCRP & $1.068(1.030-1.107)$ & $<0.001$ & $1.056(1.019-1.094)$ & $<0.05$ & - & - \\
\hline
\end{tabular}

Notes: Model I: Not adjusted. Model 2: Adjusted for age, male gender, current smoking, current alcohol use, physical activity, and education attainment. Model 3: Adjusted for age, male gender, current smoking, current alcohol use, physical activity, education attainment, fasting blood glucose, and waist circumference.

Abbreviations: LHR, lymphocyte to high-density lipoprotein cholesterol ratio; hsCRP, hypersensitive C-reactive protein. 


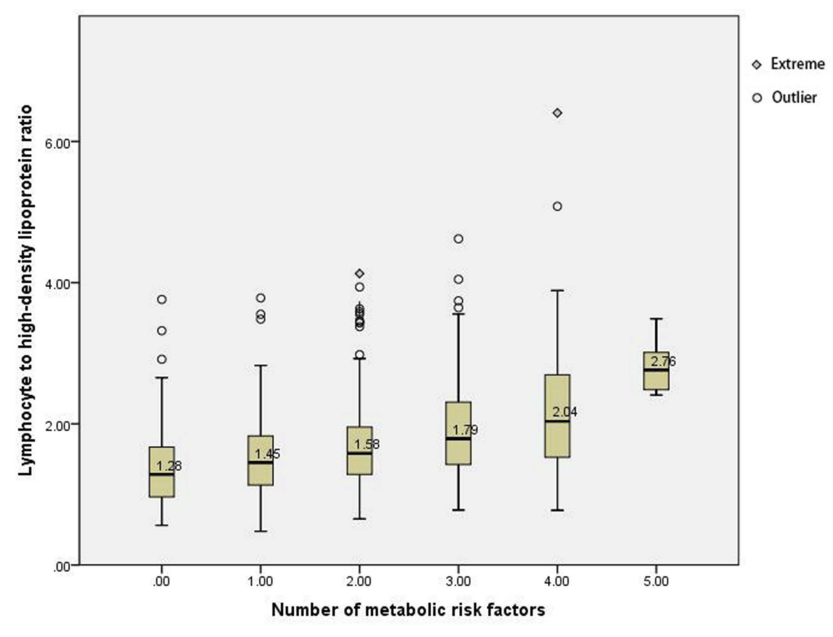

Figure I Relationship between the increase in MetS severity (based on the number of metabolic risk factors) and lymphocyte to high-density lipoprotein ratio. $* p<0.05$

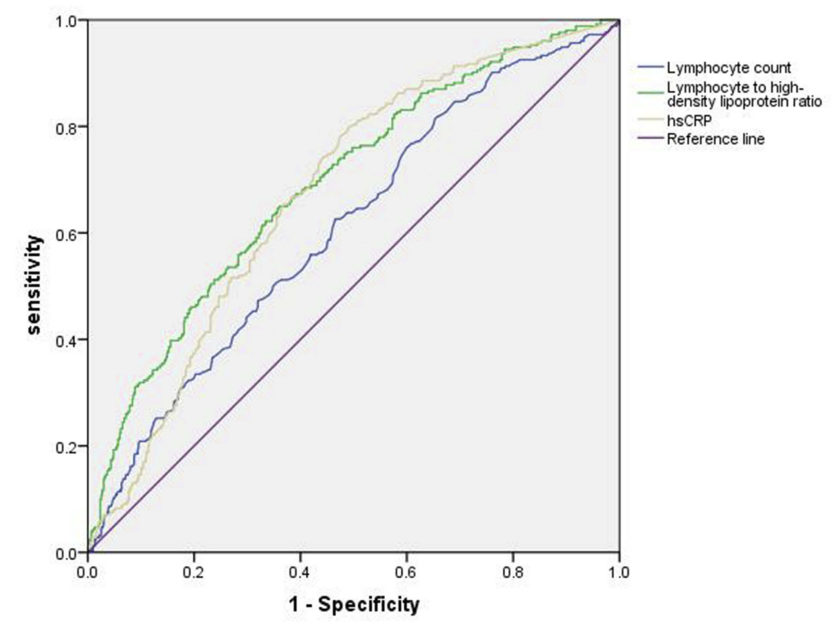

Figure 2 ROC curve analysis of the value of total lymphocyte count, lymphocyte to high-density lipoprotein ratio (LHR), and high-sensitivity C-reactive protein (hsCRP) for predicting MetS.

adipocytes stimulate the migration of adipose tissue lymphocytes, and these lymphocytes can potentiate insulin-mediated lipogenesis by local paracrine signaling. ${ }^{37}$

HDL-C can prevent the migration of macrophages in atherosclerosis and promote the export of oxidized-LDL-C from these cells, so it has anti-inflammatory and anti-lipid properties. $^{13}$ Therefore, LHR may be a novel marker of inflammation that can predict the occurrence and severity of MetS. LHR is an easily accessible marker that is less expensive than other inflammation markers such as cytokines (e.g., monocyte chemoattractant protein [MCP]-1). However, LHR has limitations, as it may be affected by many systemic inflammatory or infectious diseases as well as anti-inflammatory and anti-lipid treatments.
Our research has several limitations. First, this study is a single-center cross-sectional epidemiological survey that lacks an analysis of the causal relationship between LHS and MetS. A prospective cohort study is needed to clarify this issue. The absence of simultaneous assessment of cytokines, adipokines, CRP, and other inflammatory markers is another limitation of this study. Additionally, because we only studied residents who were willing to participate, the residents with more comorbidities and those who were not employed may have participated at a higher rate, which may have led to selection bias. In addition, we only screened the study population based on the study examination and their medical history, which may have affected the accuracy of the results (cardiac ultrasound, chest radiographs, tumor markers, etc. need to be added to exclude specific diseases).

\section{Funding}

This study was supported by Risk factors and prediction model of chronic kidney disease caused by metabolic syndrome: A multicentric prospective cohort study Clinical trial training project of Southern Medical University (LC2016PY047, 2016), Science and Technique Program of Guangzhou (201604020015, 2015), and South Wisdom Valley Innovative Research Team Program (CXTD-004, 2014), The National Natural Science Foundation of China (81873620).

\section{Disclosure}

The authors report no conflicts of interest in this work.

\section{References}

1. Tariq H, Nayudu S, Akella S, Glandt M, Chilimuri S. Non-alcoholic fatty pancreatic disease: a review of literature. Gastroenterol Res. 2016;9(6):87-91. doi:10.14740/gr731w

2. Saklayen MG. The global epidemic of the metabolic syndrome. Curr Hypertens Rep. 2018;20(2):12. doi:10.1007/s11906-018-0812-z

3. McCracken E, Monaghan M, Sreenivasan S. Pathophysiology of the metabolic syndrome. Clin Dermatol. 2018;36(1):14-20. doi:10.1016/j. clindermatol.2017.09.004

4. Oda E. Metabolic syndrome: its history, mechanisms, and limitations. Acta Diabetol. 2012;49(2):89-95. doi:10.1007/s00592-011-0309-6

5. Nebeck K, Gelaye B, Lemma S, et al. Hematological parameters and metabolic syndrome: findings from an occupational cohort in Ethiopia. Diabetes Metab Syndr. 2012;6(1):22-27. doi:10.1016/j.dsx.2012.05.009

6. Lim HJ, Seo MS, Shim JY, Kim KE, Shin YH, Lee YJ. The association between platelet count and metabolic syndrome in children and adolescents. Platelets. 2015;26(8):758-763. doi:10.3109/09537104.2014.995613

7. Yang H, Fu YQ, Yang B, et al. Positive association between the metabolic syndrome and white blood cell counts in Chinese. Asia Pac J Clin Nutr. 2017;26(1):141-147. doi:10.6133/apjen.102015.13

8. Karaman A, Aydin H, Geckinli B, Cetinkaya A, Karaman S. DNA damage is increased in lymphocytes of patients with metabolic syndrome. Mutat Res Genet Toxicol Environ Mutagen. 2015;782:30-35. doi:10.1016/j.mrgentox.2015.03.009 
9. Berhane M, Melku M, Amsalu A, Enawgaw B, Getaneh Z, Asrie F. The role of neutrophil to lymphocyte count ratio in the differential diagnosis of pulmonary tuberculosis and bacterial community-acquired pneumonia: a cross-sectional study at ayder and Mekelle Hospitals, Ethiopia. Clin Lab. 2019;65(4). doi:10.7754/Clin.Lab.2018.180833

10. Adams-Huet B, Jialal I. The neutrophil count is superior to the neutrophil/lymphocyte ratio as a biomarker of inflammation in nascent metabolic syndrome. Ann Clin Biochem. Prepublish Jul, 19, 2019. doi:10.1177/0004563219866221

11. Stentz FB, Kitabchi AE. Transcriptome and proteome expressions involved in insulin resistance in muscle and activated T-lymphocytes of patients with type 2 diabetes. Genomics Proteomics Bioinformatics. 2007;5(3-4):216-235. doi:10.1016/S1672-0229(08)60009-1

12. Piatkiewicz P, Czech A, Taton J, Gorski A. Investigations of cellular glucose transport and its regulation under the influence of insulin in human peripheral blood lymphocytes. Endokrynol Pol. 2010;61(2):182187.

13. Rohatgi A. High-density lipoprotein function measurement in human studies: focus on cholesterol efflux capacity. Prog Cardiovasc Dis. 2015;58(1):32-40. doi:10.1016/j.pcad.2015.05.004

14. Wu S, Lin $\mathrm{H}$, Zhang $\mathrm{C}$, et al. Association between erythrocyte parameters and metabolic syndrome in urban Han Chinese: a longitudinal cohort study. BMC Public Health. 2013;13:989. doi:10.1186/ 1471-2458-13-989

15. Wang YY, Lin SY, Liu PH, Cheung BM, Lai WA. Association between hematological parameters and metabolic syndrome components in a Chinese population. J Diabetes Complications. 2004;18 (6):322-327. doi:10.1016/S1056-8727(04)00003-0

16. Mardi T, Toker S, Melamed S, et al. Increased erythropoiesis and subclinical inflammation as part of the metabolic syndrome. Diabetes Res Clin Pract. 2005;69(3):249-255. doi:10.1016/j.diabres.2005.01.005

17. Kim JA, Choi YS, Hong JI, Kim SH, Jung HH, Kim SM. Association of metabolic syndrome with white blood cell subtype and red blood cells. Endocr J. 2006;53(1):133-139. doi:10.1507/endocrj.53.133

18. Kawamoto R, Tabara Y, Kohara K, et al. Hematological parameters are associated with metabolic syndrome in Japanese community-dwelling persons. Endocrine. 2013;43(2):334-341. doi:10.1007/s12020-0129662-7

19. Facchini FS, Carantoni M, Jeppesen J, Reaven GM. Hematocrit and hemoglobin are independently related to insulin resistance and compensatory hyperinsulinemia in healthy, non-obese men and women. Metabolism. 1998;47(7):831-835. doi:10.1016/s0026-0495(98)90121-4

20. Nakanishi N, Suzuki K, Tatara K. Haematocrit and risk of development of type 2 diabetes mellitus in middle-aged Japanese men. Diabet Med. 2004;21(5):476-482. doi:10.1111/j.1464-5491.2004.01152.x

21. Tamariz LJ, Young JH, Pankow JS, et al. Blood viscosity and hematocrit as risk factors for type 2 diabetes mellitus: the atherosclerosis risk in communities (ARIC) study. Am J Epidemiol. 2008;168 (10):1153-1160. doi:10.1093/aje/kwn243

22. Tanigawa T, Iso H, Yamagishi K, et al. Association of lymphocyte sub-populations with clustered features of metabolic syndrome in middle-aged Japanese men. Atherosclerosis. 2004;173(2):295-300. doi:10.1016/j.atherosclerosis.2003.12.019

23. Chen W, Srinivasan SR, Xu J, Berenson GS. Black-white divergence in the relation of white blood cell count to metabolic syndrome in preadolescents, adolescents, and young adults: the Bogalusa heart study. Diabetes Care. 2010;33(11):2474-2476. doi:10.2337/dc100619
24. Su BY, Tian CF, Gao BL, Tong YH, Zhao XH, Zheng Y. Correlation of the leucocyte count with traditional and non-traditional components of metabolic syndrome. Postgrad Med. 2016;128(8):805-809. doi:10.1080/00325481.2016.1243980

25. Lao XQ, Thomas NG, Jiang C, et al. White blood cell count and the metabolic syndrome in older Chinese: the Guangzhou Biobank cohort study. Atherosclerosis. 2008;201(2):418-424. doi:10.1016/j. atherosclerosis.2007.12.053

26. Pasini E, Flati V, Paiardi S, et al. Intracellular molecular effects of insulin resistance in patients with metabolic syndrome. Cardiovasc Diabetol. 2010;9:46. doi:10.1186/1475-2840-9-46

27. Bersch N, Groopman JE, Golde DW. Natural and biosynthetic insulin stimulates the growth of human erythroid progenitors in vitro. J Clin Endocrinol Metab. 1982;55(6):1209-1211. doi:10.1210/jcem-55-61209

28. Dainiak N, Kreczko S. Interactions of insulin, insulinlike growth factor II, and platelet-derived growth factor in erythropoietic culture. J Clin Invest. 1985;76(3):1237-1242. doi:10.1172/JCI11 2079

29. Sawada K, Krantz SB, Dessypris EN, Koury ST, Sawyer ST. Human colony-forming units-erythroid do not require accessory cells, but do require direct interaction with insulin-like growth factor I and/or insulin for erythroid development. J Clin Invest. 1989;83(5):17011709. doi:10.1172/JCI114070

30. Widness JA, Susa JB, Garcia JF, et al. Increased erythropoiesis and elevated erythropoietin in infants born to diabetic mothers and in hyperinsulinemic rhesus fetuses. J Clin Invest. 1981;67(3):637-642. doi:10.1172/JCI110078

31. Hagita S, Osaka M, Shimokado K, Yoshida M, Gimble JM. Adipose inflammation initiates recruitment of leukocytes to mouse femoral artery: role of adipo-vascular axis in chronic inflammation. PLoS One. 2011;6(5):e19871. doi:10.1371/journal.pone.0019871

32. Meng W, Zhang C, Zhang Q, et al. Association between leukocyte and metabolic syndrome in urban Han Chinese: a longitudinal cohort study. PLoS One. 2012;7(11):e49875. doi:10.1371/journal.pone.004 9875

33. Cabrales P, Han G, Nacharaju P, Friedman AJ, Friedman JM. Reversal of hemoglobin-induced vasoconstriction with sustained release of nitric oxide. Am J Physiol Heart Circ Physiol. 2011;300 (1):H49-H56. doi:10.1152/ajpheart.00902.2010

34. Nakanishi N, Suzuki K, Tatara K. White blood cell count and clustered features of metabolic syndrome in Japanese male office workers. Occup Med (Lond). 2002;52(4):213-218. doi:10.1093/occmed/ 52.4.213

35. Shankar A, Klein BE, Klein R. Relationship between white blood cell count and incident hypertension. Am J Hypertens. 2004;17(3):233239. doi:10.1016/j.amjhyper.2003.11.005

36. Okamoto Y, Folco EJ, Minami M, et al. Adiponectin inhibits the production of CXC receptor 3 chemokine ligands in macrophages and reduces T-lymphocyte recruitment in atherogenesis. Circ Res. 2008;102(2):218-225. doi:10.1161/CIRCRESAHA.107.164988

37. Duffaut C, Zakaroff-Girard A, Bourlier V, et al. Interplay between human adipocytes and T lymphocytes in obesity: CCL20 as an adipochemokine and $\mathrm{T}$ lymphocytes as lipogenic modulators. Arterioscler Thromb Vasc Biol. 2009;29(10):1608-1614. doi:10.11 61/ATVBAHA.109.192583 


\section{Publish your work in this journal}

Diabetes, Metabolic Syndrome and Obesity: Targets and Therapy is an international, peer-reviewed open-access journal committed to the rapid publication of the latest laboratory and clinical findings in the fields of diabetes, metabolic syndrome and obesity research. Original research, review, case reports, hypothesis formation, expert opinion and commentaries are all considered for publication. The manuscript management system is completely online and includes a very quick and fair peer-review system, which is all easy to use. Visit http://www.dovepress.com/testimonials.php to read real quotes from published authors.

Submit your manuscript here: https://www.dovepress.com/diabetes-metabolic-syndrome-and-obesity-targets-and-therapy-journal 